\title{
Transvaginal Sonographic Assessment of the Cervix for Prediction of Successful Induction of Labor in Nulliparous Women
}

\author{
Mohamed Abdelhameed Abdelhafeez, Alaa Eldin Elguindy, \\ Mohamed Abu-El-Fetoh Mohamed Hamed, Maii Nawara \\ Department of Obstetrics and Gynecology, Ain Shams University, Cairo, Egypt \\ Email: maii_nawara@hotmail.com
}

How to cite this paper: Abdelhafeez, M.A., Elguindy, A.E., Hamed, M.A.M. and Nawara, M. (2020) Transvaginal Sonographic Assessment of the Cervix for Prediction of Successful Induction of Labor in Nulliparous Women. Open Journal of Obstetrics and Gynecology, 10, 892-901.

https://doi.org/10.4236/ojog.2020.1070084

Received: June 16, 2020

Accepted: July 11, 2020

Published: July 14, 2020

Copyright $\odot 2020$ by author(s) and Scientific Research Publishing Inc. This work is licensed under the Creative Commons Attribution International License (CC BY 4.0).

http://creativecommons.org/licenses/by/4.0/

(c) (i) Open Access

\begin{abstract}
Background: Induction of labor is commonly performed in obstetric practice. Many methods have been suggested as good predictors of the outcome of labor induction, yet none of them is satisfactory enough. Our study aims to assess cervical length and uterocervical angle measured by transvaginal ultrasound as predictors of successful induction of labor. Methods: Prospective cohort study conducted in Ain Shams University Maternity hospital over 150 nulliparous women undergoing induction of labor, in the period between May 2018 and August 2019. Transvaginal sonographic measurement of cervical length and uterocervical angle was done before induction of labor by prostaglandins. The patients were followed up till delivery and the outcome was recorded. Results: The best cut-off value of cervical length for prediction of success of labor induction was $32.3 \mathrm{~mm}$ with $60 \%$ sensitivity and $56 \%$ specificity and the best cut-off value of uterocervical angle was 110.2 degrees with $87 \%$ sensitivity and $93 \%$ specificity. The cervical length showed a significant negative correlation while the uterocervical angle showed a significant positive correlation with the success of labor induction. Conclusion: Cervical length and uterocervical angle are good predictors of successful labor induction.
\end{abstract}

\section{Keywords}

Induction of Labor, Cervical Length, Uterocervical Angle

\section{Introduction}

Induction of labor is a common obstetric procedure, as more than $20 \%$ of pregnancies undergo the induction of labor for various indications such as post-date pregnancy, prelabor rupture of membranes, elective labor and medical disorders 
[1]. It is defined as artificial stimulation of the uterus to start labor, either pharmacologically using prostaglandins or oxytocin, or mechanically by amniotomy, membrane sweeping or intrauterine balloon insertion [2].

Failed induction of labor has usually referred to cesarean section performed during the latent phase which extended beyond 15 hours of starting oxytocin. Maternal and neonatal complications are associated with longer latent phase, such as cesarean section, chorioamnionitis, postpartum hemorrhage, neonatal seizures and need for neonatal ICU admission [3]. Hence, there is a need for good prediction of the outcome of labor induction.

Bishop score is commonly used for the prediction of successful delivery, yet its sensitivity is $23 \%-64 \%$. Recently, sonographic assessment of cervical measurements was shown to properly predict labor outcome [4] [5] [6] [7].

The most commonly used sonographic parameter, the cervical length (CL), has shown a moderate capacity to predict outcome of labor induction [8]. Recently, the uterocervical angle (UCA); defined as the angle between the anterior uterine wall and the cervical canal, has been reported as a good predictor of successful induction of labor [9].

The present study was an effort to determine whether ultrasound cervixmeasurement (length and uterocervical angle) may well predict the success of labor induction and if so their predictive characteristics.

\section{Methods}

\subsection{Study Design}

This prospective cohort study was conducted in Ain Shams University Maternity hospital over 150 nulliparous women undergoing induction of labor, in the period between May 2018 and August 2019. This study was done after approval of the ethical committee of the department of obstetrics and gynecology, faculty of medicine, Ain Shams University. Informed consent was taken from all participants before recruitment in the study, and after explaining the purpose and procedures of the study. We obtained and retained the written, signed informed consent of each subject.

\subsection{Patients}

Our criteria for inclusion were primigravidas with gestational age of 38 or more weeks, singleton pregnancy, vertex presentation, intact membranes with no uterine contractions. Women were excluded if they had a suspected macrosomic fetus, fetal anomalies, history of previous uterine or cervical surgery or other obstetric contraindications to vaginal delivery such as active genital herpes or placenta previa.

\subsection{Procedure}

Study candidates were subjected to full history taking, general, abdominal and pelvic examination. Transvaginal ultrasound measurement of cervical length and uterocervical angle was performed before starting labor induction. 
The cervical length (CL) was measured tracing a single straight line from the internal to external os. Uterocervical angle (UCA) measurement was obtained by placing the first ray from the internal os to the external os through the endocervical canal and by placing the second ray to delineate the lower uterine segment (Figure 1). For each parameter, three measurements were obtained and the mean value was recorded. All transvaginal imaging was done by a single sonographer using 4- to 9-MHz IC5-9D (Voluson E6; GE Healthcare, Milwaukee, WI).

Labor induction was performed by inserting $25 \mu \mathrm{g}$ of vaginal misoprostol every 6 hours, until adequate cervical ripening has been reached (Bishop score $>$ 7), spontaneous rupture of membranes or 24 hours have elapsed (classified as failed induction). Candidates who responded successfully to induction were assessed for possible augmentation of labor by amniotomy or oxytocin infusion.

\subsection{Outcomes}

Our primary outcome was correlation between pre-induction CL and UCA measurements and successful induction of labor defined as adequate uterine contractions causing cervical changes or rupture of membranes.

\subsection{Sample Size Estimation \& Statistical Analysis}

Sample size was calculated using STATA program, setting the type-1 error $(\alpha)$ at 0.05 and the power $(1-\beta)$ at 0.8 . Result from previous study [10], showed that using ROC curve, the best cut-off point for the prediction of successful induction was $28 \mathrm{~mm}$ for cervical length with a sensitivity of $87 \%$ and a specificity of $71 \%$, with a successful induction in about $50 \%$ of primigravid cases. Calculation according to these values produced a minimal sample size of 88 cases (including 44 with successful induction). We included 150 women for possible attrition.

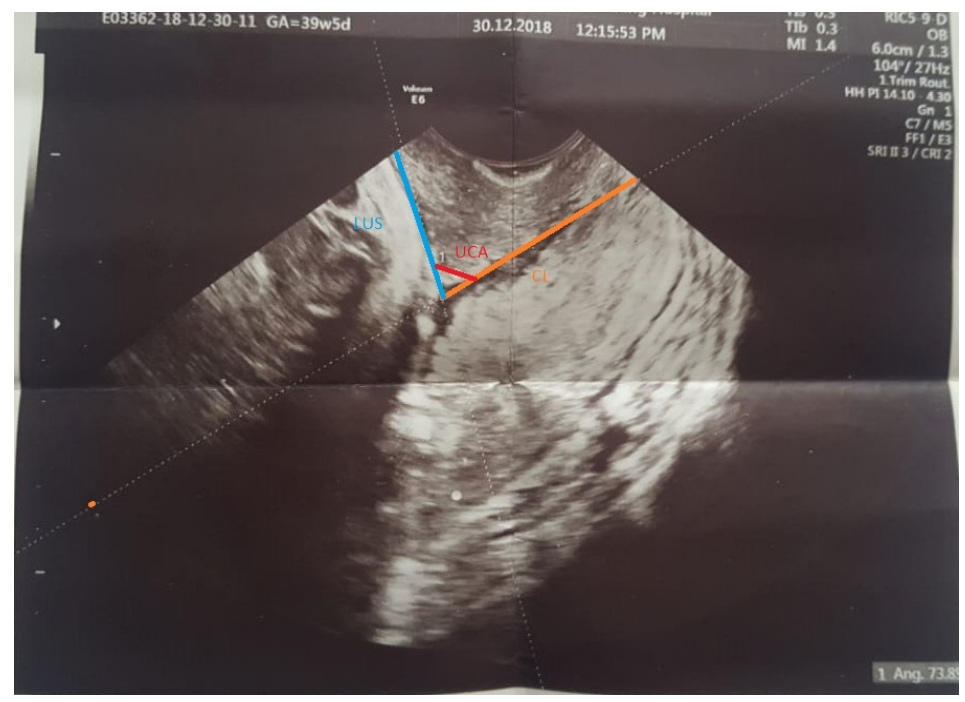

Figure 1. Measurement of CL (orange line) and UCA (red angle between lower uterine segment, blue and cervical axis, orange). 
The collected data was revised, coded, tabulated and introduced to a PC using Statistical package for Social Science (SPSS 20.0.1 for windows; SPSS Inc, Chicago, IL, 2001). Quantitative variables are expressed as mean and SD, or Median and Interquartile range (IQR) according to distribution of data. Qualitative variables are expressed as frequencies and percents. Student $t$ test and Mann Whitney Test was used to compare a continuous variable between two study groups. Chi square test was used to examine the relationship between Categorical variables. A P-value $<0.05$ was considered statistically significant. For different probability cutoffs, the sensitivity and specificity were calculated. In the comparison of the receiver operating characteristics curves, the area under the curve is usually the best discriminator.

\section{Results}

The study included 150 primigravid women, with a mean age of 23.6 years, BMI of $27.7 \mathrm{~kg} / \mathrm{m}^{2}$ and a median gestational age of 40 weeks (Table 1). Out of the 150 cases, 115 had a successful induction of labor with 97 women achieving a vaginal delivery, while 35 women had a failed induction and ended up delivering by cesarean section. Eighteen women in the successful induction group eventually delivered by cesarean section ( 11 due to fetal distress and 7 due to failed progress of labor). There was a significant difference between successful and failed induction groups regarding maternal BMI and neonatal birth weight, pre-induction CL and UCA (Table 2), yet there was no difference between both groups in indications for induction (Table 3). The best cut-off value of cervical length for prediction of success of labor induction was $32.3 \mathrm{~mm}$ with $60 \%$ sensitivity and $56 \%$ specificity and the best cut-off value of uterocervical angle was $110.2 \mathrm{de}$ grees with $87 \%$ sensitivity and $93 \%$ specificity (Table 4 ). The cervical length showed a significant negative correlation while the uterocervical angle showed a significant positive correlation with the success of labor induction (Table 5). There was a highly significant statistical difference between those who delivered vaginally and those who delivered by cesarean section in pre-induction cervical length and uterocervical angle (Table 6). See Figures 2-5.

Table 1. Baseline data of the studied cases.

\begin{tabular}{|c|c|}
\hline \multicolumn{2}{|c|}{ Variable } \\
\hline \multicolumn{2}{|c|}{ Age (Years) } \\
\hline Mean \pm SD Range & $\begin{array}{c}23.6 \pm 2.7 \\
(18-30)\end{array}$ \\
\hline \multicolumn{2}{|c|}{$\mathrm{BMI}\left(\mathrm{Kg} / \mathrm{m}^{2}\right)$} \\
\hline Mean \pm SD Range & $\begin{array}{c}27.7 \pm 2.8 \\
(21.6-36.4)\end{array}$ \\
\hline \multicolumn{2}{|c|}{ Gestational age (Weeks) } \\
\hline Median Range & $\begin{array}{c}40 \pm 2 \\
(38-42)\end{array}$ \\
\hline
\end{tabular}


Table 2. Comparison of successful and failed induction according to fetal and maternal characteristics and pre-induction cervical measurements.

\begin{tabular}{|c|c|c|c|c|}
\hline Variable & Successful $(n=115)$ & failed $(n=35)$ & t-test & $P$ value \\
\hline \multicolumn{5}{|c|}{ Birth weight (gm): } \\
\hline Mean \pm SD & $3190.4 \pm 346.9$ & $3636.6 \pm 386.7$ & 3.13 & $0.035(S)$ \\
\hline \multicolumn{5}{|c|}{ Gestational age (weeks): } \\
\hline Mean \pm SD & $38.9 \pm 1.0$ & $39.1 \pm 0.9$ & 0.853 & 0.395 (NS) \\
\hline \multicolumn{5}{|c|}{ BMI $\left(\mathrm{Kg} / \mathrm{m}^{2}\right)$ : } \\
\hline Mean \pm SD Range & $\begin{array}{l}27.6 \pm 2.9 \\
(21.6-34)\end{array}$ & $\begin{array}{l}29.0 \pm 2.6 \\
(22-36.4)\end{array}$ & 2.55 & $0.011(S)$ \\
\hline \multicolumn{5}{|c|}{ Cervical length (mm): } \\
\hline Mean \pm SD & $32.4 \pm 3.0$ & $33.6 \pm 2.5$ & 2.03 & $0.044(S)$ \\
\hline \multicolumn{5}{|c|}{ Uterocervical angle $\left({ }^{\circ}\right)$ : } \\
\hline Mean \pm SD & $115.4 \pm 11.4$ & $109.5 \pm 7.8$ & 2.86 & $0.004(S)$ \\
\hline
\end{tabular}

S: significant, NS: non-significant.

Table 3. Comparison of successful and failed induction according to indications of induction.

\begin{tabular}{|c|c|c|c|c|c|c|}
\hline \multirow[t]{2}{*}{ Variable } & \multicolumn{2}{|c|}{ Successful $(n=115)$} & \multicolumn{2}{|c|}{ failed $(n=35)$} & \multirow[t]{2}{*}{$x^{2}$} & \multirow[t]{2}{*}{$P$ value } \\
\hline & No. & $\%$ & No. & $\%$ & & \\
\hline \multicolumn{7}{|c|}{ Indications: } \\
\hline $\mathrm{DM}$ & 7 & 6.1 & 8 & 22.9 & & \\
\hline Hypertension & 17 & 14.8 & 5 & 14.3 & & \\
\hline Oligohydraminos & 34 & 29.6 & 9 & 25.7 & 8.58 & $0.72(\mathrm{NS})$ \\
\hline Post term & 4 & 3.5 & 1 & 2.9 & & \\
\hline PROM & 53 & 46.1 & 12 & 34.3 & & \\
\hline
\end{tabular}

NS: non-significant.

Table 4. Cervical length and Uterocervical angle as predictors of successful induction.

\begin{tabular}{cccccccc}
\hline & Area & P & Sensitivity & Specificity & Best cut off & \multicolumn{2}{c}{$95 \%$ Confidence Interval } \\
\hline & & & & & Lower Bound & Upper Bound \\
CL & $\mathbf{0 . 6 2 5}$ & $0.00^{* *}$ & $60.0 \%$ & $56.0 \%$ & 32.3 & 0.532 & 0.718 \\
UCA & $\mathbf{0 . 8 3 5}$ & 0.017 & $\mathbf{8 7 . 0 \%}$ & $93.0 \%$ & 110.2 & 0.744 & 0.927 \\
\hline
\end{tabular}

Table 5. Correlation between cervical measurements and successful induction.

\begin{tabular}{ccc}
\hline Variable & \multicolumn{2}{c}{ Successful induction } \\
\hline Cervical length & $\mathbf{P}$ & (S) 0.02 \\
Uterocervical angle & -0.184 & (S) 0.02
\end{tabular}

R for correlation coefficient of spearman's correlation, S: significant. 
Table 6. Comparison between normal vaginal delivery and cesarean section according to pre-induction cervical measures.

\begin{tabular}{ccccc}
\hline Variable & NVD $(\mathrm{n}=\mathbf{9 7})$ & C.S $(\mathrm{n}=53)$ & t-test & P value \\
\hline & \multicolumn{2}{c}{ Cervicallength $(\mathrm{mm}):$} & & \\
Mean \pm SD & $31.8 \pm 2.7$ & $34.2 \pm 2.7$ & 5.14 & $<0.001(\mathrm{HS})$ \\
& \multicolumn{2}{c}{ Uterocervical angle $\left(^{\circ}\right):$} \\
Mean \pm SD & $116.3 \pm 7.6$ & $103.5 \pm 10.8$ & & \\
\end{tabular}

HS: highly significant.

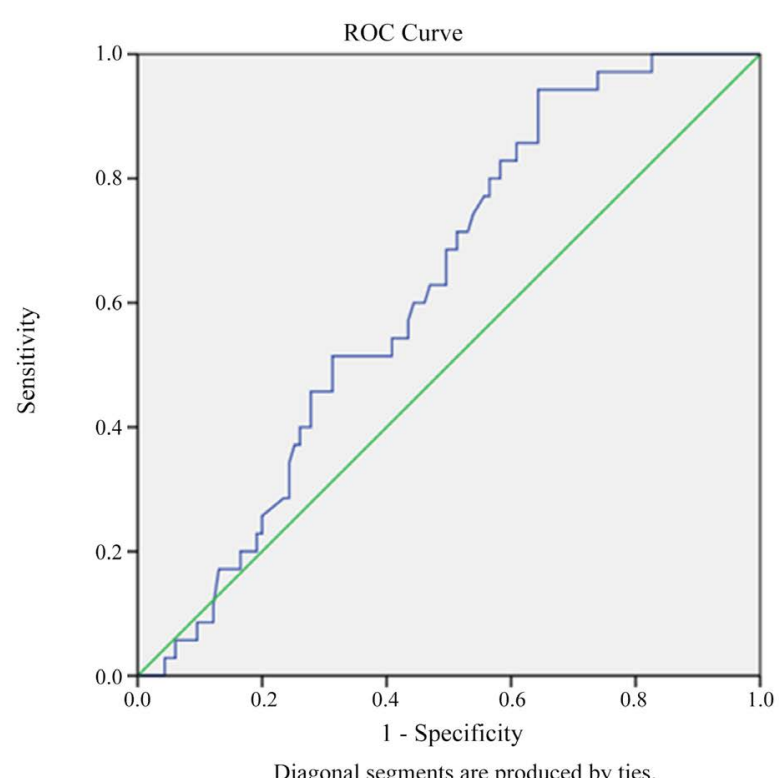

Diagonal segments are produced by ties.

Figure 2. ROC Curve for cervical length as a predictor of successful induction.

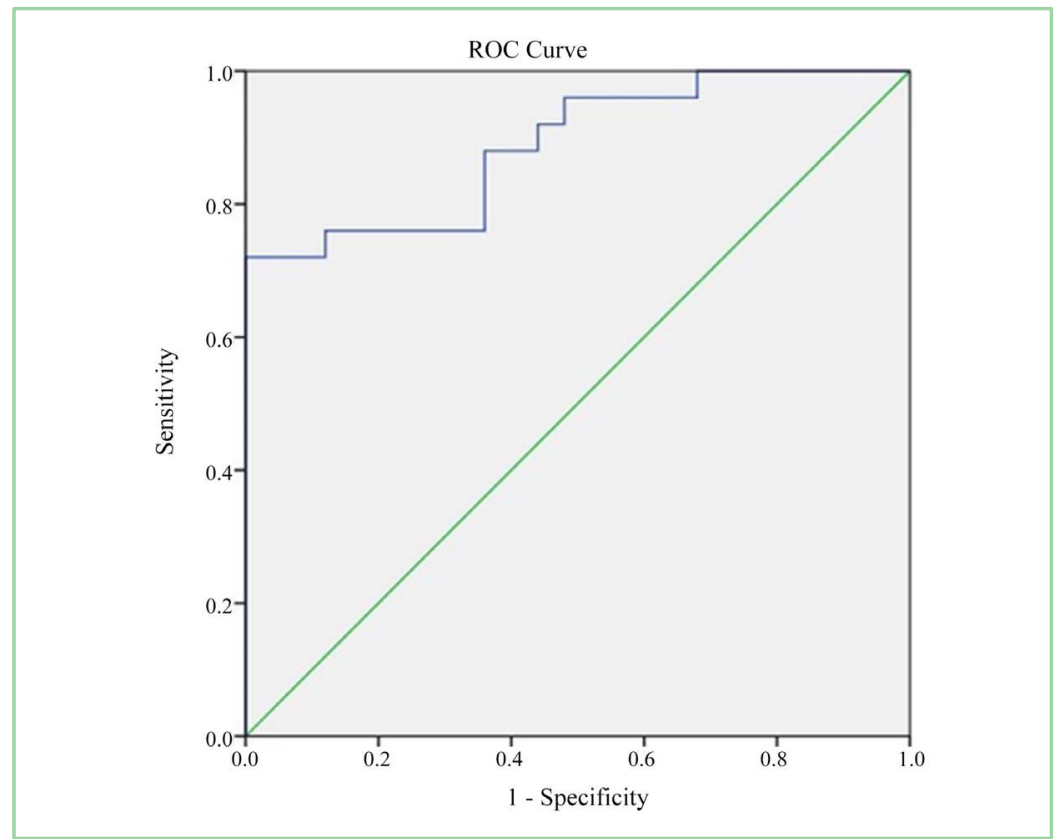

Figure 3. ROC Curve for uterocervical angle as a predictor of successful induction. 


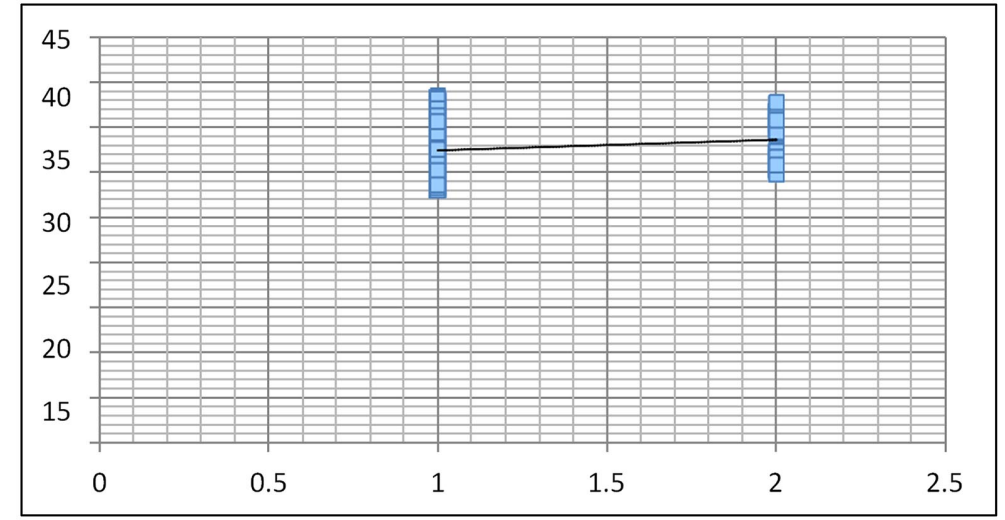

Figure 4. Correlation between cervical length and success of induction.

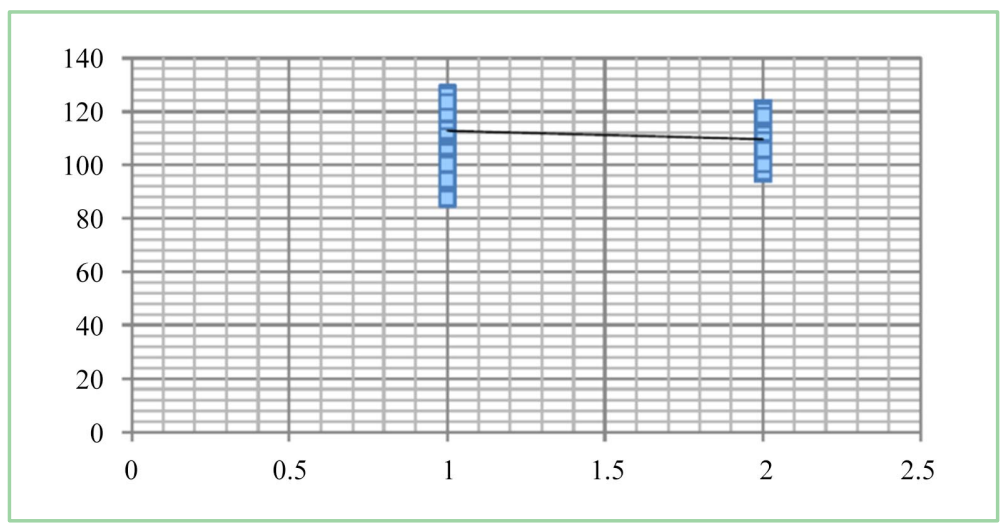

Figure 5. Correlation between utero cervical angle and success of induction.

\section{Discussion}

Our prospective cohort study performed on 150 nulliparous women showed that both; CL and UCA are good predictors of successful labor induction. The best cut-off for CL was $32.3 \mathrm{~mm}$ with a sensitivity of $60 \%$ and a specificity of $56 \%$. The best cut-off for UCA was 110.2 degrees with a sensitivity of $87 \%$ and specificity of $93 \%$. There was a highly significant difference in CL and UCA between women who delivered vaginally and those who underwent a cesarean section.

The cervix, with its high collagen content and ligamentous support, has an undeniable role in labor. That explains why studies about the prediction of labor induction success are mainly focused on cervical parameters. Studies investigating cervical parameters show conflicting results due to non-uniformity of outcomes. Some studies defined their primary outcome as successful vaginal delivery, regardless of other factors that might necessitate a cesarean section such as fetal distress. Other studies defined their primary outcome as successful induction of labor, relying on adequate uterine contractions or cervical changes, regardless of the mode of delivery.

The cervix is prone to alteration by pressure from pelvic organs, or by enlarging uterus or fetus. Theoretically speaking, cervical effacement, a pivotal component of the process of labor, shortens the cervix and stretches the lower ute- 
rine segment. Thus, women with a favorable cervix are expected to show a short cervical length and a wide uterocervical angle by ultrasound.

In literature, the results about the reliability of sonographic measurement of cervical length to predict outcome of labor induction are conflicting. Some studies suggested its high predictive value with a cut-off of $28 \mathrm{~mm}$, and its higher sensitivity and specificity compared with Bishop score [10] [11] [12] [13]. While others showed it was only inferior to Bishop score [14] [15]. Our cut-off value for cervical length is higher than calculated by previous studies due to difference in parities of included study subjects, and differences in methods of induction.

Basic physics constitute a major role in correlating the uterocervical angle and prediction of labor. The force the uterus exerts on the cervix varies according to the uterocervical angle; the uterine contraction on an acute uterocervical angle strengthens the closure of the endo-cervical canal, whereas the same uterine force applied on an obtuse angle can hasten the opening of the cervix resulting in rapid emptying of the uterine contents into the vagina. A wider UCA is thought to result in more direct, linear outlet of uterine contents [16]. That is why it has been primarily investigated as a predictor of preterm labor. A wider UCA has shown a high predictive value for preterm birth [17]. It has also been studied for prediction of mid-trimester pregnancy termination success, showing high sensitivity and specificity [18]. CL and UCA were also studied for differentiating true from the false labor, it was found that the true labor group had shorter CL and larger UC angle. The optimal cut-off for UCA was found to be 123 degrees [19].

More recent studies in literature investigated the correlation between successful labor induction and uterocervical angle. Eser and Ozkaya reported a cut-off of 97 degrees as a predictor of failed induction of labor [9]. Dagdeviren et al. reported that pre-induction UCA was not a good predictor of the outcome of labor induction, yet patients with more obtuse UCAs were more likely to have a shorter duration of active phase although their results showed that UCAs significantly differed between the modes of delivery subgroups. The median UCA was significantly higher in patients who delivered vaginally than in patients who delivered via cesarean section. The median UCA value was least in women who had a successful induction of labor but ended up having a cesarean section [16].

The limitation of our study is that sonographic assessment was done only once, before labor induction, while labor is a dynamic process with continuous cervical changes resulting from uterine contractions.

\section{Conclusion}

Cervical length and uterocervical angle are correlated with outcome of induction of labor, and may be used to predict successful induction of labor.

\section{Conflicts of Interest}

The authors declare no conflicts of interest regarding the publication of this paper. 


\section{References}

[1] Martin, J.A., Hamilton, B.E., Osterman, M.J., Curtin, S.C. and Matthews, T.J. (2015) Births: Final Data for 2013. National Vital Statistics Reports, 64, 1-65.

[2] WHO (2018) Recommendations: Induction of Labour at or beyond Term. World Health Organization, Geneva.

[3] Grobman, W.A., Bailit, J., Lai, Y., Reddy, U.M., Wapner, R.J., Varner, M.W., Thorp, J.M., Leveno, K.J., Caritis, S.N., Prasad, M., Tita, A.T.N., Saade, G., Sorokin, Y., Rouse, D.J., Blackwell, S.C. and Tolosa, J.E. (2018) Defining Failed Induction of Labor. American Journal of Obstetrics \& Gynecology, 218, 122.e1-122.e8.

[4] Tan, P.C., Vallikkannu, N., Suguna, S., Quek, K.F. and Hassan, J. (2007) Transvaginal Sonographic Measurement of Cervical Length vs. Bishop Score in Labor Induction at Term: Tolerability and Prediction of Cesarean Delivery. Ultrasound in Obstetrics \& Gynecology, 29, 568-573. https://doi.org/10.1002/uog.4018

[5] Elghorori, M.R., Hassan, I., Dartey, W. and Abdel-Aziz, E. (2006) A Way to Lend Objectivity to Bishop Score. Journal of Obstetrics and Gynaecology, 26, 311-316. https://doi.org/10.1080/01443610600594922

[6] Laencina, A.M., Sanchez, F.G., Gimenez, J.H., Martínez, M.S., Valverde Martínez, J.A. and Vizcaíno, V.M. (2007) Comparison of Ultrasonographic Cervical Length and the Bishop Score in Predicting Successful Labor Induction. Acta Obstetricia et Gynecologica Scandinavica, 86, 799-804. https://doi.org/10.1080/00016340701409858

[7] Bueno, B., San-Frutos, L., Perez-Medina, T., Barbancho, C., Troyano, J. and Bajo, J. (2007) The Labor Induction: Integrated Clinical and Sonographic Variables That Predict the Outcome. Journal of Perinatology, 27, 4-8.

https://doi.org/10.1038/sj.jp.7211619

[8] Verhoeven, C.J.M., Opmeer, B.C., Oei, S.G., Latour, V., van der Post, J.A.M. and Mol, B.W.J. (2013) Transvaginal Sonographic Assessment of Cervical Length and Wedging for Predicting Outcome of Labor Induction at Term: A Systematic Review and Meta-Analysis. Ultrasound in Obstetrics \& Gynecology, 42, 500-508. https://doi.org/10.1002/uog.12467

[9] Eser, A. and Ozkaya, E. (2020) Uterocervical Angle: An Ultrasound Screening Tool to Predict Satisfactory Response to Labor Induction. The Journal of Maternal-Fetal \& Neonatal Medicine, 33, 1295-1301.

[10] Pandis, G.K., Papageorghiou, A.T., Ramanathan, V.G., Thompson, M.O. and Nicolaides, K.H. (2001) Pre-Induction Sonographic Measurement of Cervical Length in the Prediction of Successful Induction of Labor. Ultrasound in Obstetrics and Gynecology, 18, 623-628. https://doi.org/10.1046/j.0960-7692.2001.00580.x

[11] Boozarjomehri, F., Timor-Tritsch, I. and Chao, C.R. (1994) Transvaginal Ultrasound Evaluation of the Cervix before Labor: Presence of Cervical Wedging Is Associated with Shorter Duration of Induced Labor. American Journal of Obstetrics \& Gynecology, 171, 1081-1087. https://doi.org/10.1016/0002-9378(94)90040-X

[12] Gonen, R., Degani, S. and Ron, A. (1998) Prediction of Successful Induction of Labor: Comparison of Transvaginal Ultrasonography \& the Bishop Score. European Journal of Ultrasound, 7, 183-187. https://doi.org/10.1016/S0929-8266(98)00042-1

[13] Gokturk, U., Cavkaytar, S. and Danısman, N. (2015) Can Measurement of Cervical Length, Fetal Head Position and Posterior Cervical Angle Be an Alternative Method to Bishop Score in the Prediction of Successful Labor Induction? The Journal of Maternal-Fetal \& Neonatal Medicine, 28, 1360-1365. https://doi.org/10.3109/14767058.2014.954538 
[14] Reis, F.M., Gervasi, M.T., Florio, P., Bracalente, G., Fadalti, M., Severi, F.M. and Petraglia, F. (2003) Prediction of Successful Induction of Labor at Term: Role of Clinical History, Digital Examination, Ultrasound Assessment of the Cervix, and Fetal Fibronectin Assay. American Journal of Obstetrics \& Gynecology, 189, 1361-1367. https://doi.org/10.3109/14767058.2014.954538

[15] Roman, H., Verspyck, E., Vercoustre, L., Degre, S., Col, J.Y., Firmin, J.M., Caron, P. and Marpeau, L. (2004) Does Ultrasound Examination When the Cervix Is Unfavorable Improve the Prediction of Failed Labor Induction? Ultrasound in Obstetrics \& Gynecology, 23, 357-362. https://doi.org/10.1002/uog.1008

[16] Dagdeviren, E., Çetin, B.A., Mathyk, B.A., Koroglu, N., Topcu, E.G. and Yuksel, M.A. (2018) Can Uterocervical Angles Successfully Predict Induction of Labor in Nulliparous Women? European Journal of Obstetrics \& Gynecology and Reproductive Biology, 228, 87-91. https://doi.org/10.1016/j.ejogrb.2018.06.014

[17] Daskalakis, G., Theodora, M., Antsaklis, P., Sindos, M., Grigoriadis, T., Antsaklis, A., Papantoniou, N., Loutradis, D. and Pergialiotis, V. (2018) Assessment of Uterocervical Angle Width as a Predictive Factor of Preterm Birth: A Systematic Review of the Literature. BioMed Research International, 2018, Article ID: 1837478. https://doi.org/10.1155/2018/1837478

[18] Cetin, B.A., Mathyk, B.A., Tuten, A., Bahat, P.A., Koroglu, N. and Topcu, E.G. (2019) The Predictive Nature of Uterocervical Angles in the Termination of Second Trimester Pregnancy. The Journal of Maternal-Fetal \& Neonatal Medicine, 32, 1952-1957. https://doi.org/10.1080/14767058.2017.1421936

[19] Knight, J.C., Tenbrink, E., Onslow, M. and Pantil, A.S. (2018) Uterocervical Angle Measurement Improves Prediction of Preterm Birth in Twin Gestation. American Journal of Perinatology, 35, 648-654. https://doi.org/10.1055/s-0037-1608877 